\title{
Study on Deep Integration of Intelligent Computing and Mathematical Modeling
}

\author{
Sheng Liu \\ School of Management \\ Shanghai University of Engineering Science \\ Shanghai, China
}

\author{
Xiaoming You \\ College of Electronic and Electrical Engineering \\ Shanghai University of Engineering Science \\ Shanghai, China
}

\begin{abstract}
In order to cultivate students' scientific computing ability in the process of mathematical modeling, the important role of intelligence computing is expounded. Based on advanced and novel teaching cases, multi-disciplinary and multi-formalized teaching means, a series of teaching reform measures are put forward including course construction and teaching methods.
\end{abstract}

Keywords-mathematical modeling; intelligence computing; multidisciplinary intersecting; creative education

\section{INTRODUCTION}

Intelligent computing is to simulate the behavior of human beings or other natural organisms in processing information, and to establish theories, algorithms and systems for dealing with complex system information. It mainly faces the problem of transforming incomplete, unreliable, imprecise, inconsistent and uncertain knowledge and information into complete, reliable, accurate, consistent and definite knowledge and information ${ }^{[1]}$. Intelligent computing is a frontier subject in the development of science and technology. It is also an emerging subject with new ideas, new concepts, new theories and new technologies emerging and developing rapidly. It involves many fields of information science. It is a comprehensive application of modern signal processing, artificial neural network, machine learning, artificial intelligence and other theories and methods. It has broad application prospects in complex system modeling, machine learning and systems, systematic optimization and design.

The topic of the mathematical contest in modeling is not an abstract mathematical problem, but a simplified and challenging problem in engineering technology and management science. It covers a wide range of knowledge, including biology, medicine, economy, military, and politics and so on. In recent years, most of the topics in the Sino-US Mathematical contest in modeling represent the current trend of scientific research. There are no fixed standard answers, and they have greater flexibility for the participants to develop their creativity. The aim of the contest is to improve students' ability to solve practical problems by using mathematical modeling and computer technology and to cultivate innovative talents ${ }^{[2]}$.

\section{MATHEMATICAL Modeling PROCESS}

The mathematical model is a mathematical structure for a specific purpose, which is got by making some necessary simplifications and assumptions, and using appropriate mathematical tools, according to the unique internal law of a specific object in the real world ${ }^{[3]}$. Mathematical modeling refers to the whole process of establishing mathematical models.

Generally speaking, when practical problems need to provide quantitative results for analysis, prediction, decisionmaking, control and other aspects to the actual objects studied, it is often inseparable from the application of mathematics, and mathematical modeling is the most critical step. It is indispensable that a mathematical model of a practical problem must be checked by certain technical means, such as reasoning proof, calculation, and simulation and so on. If the established mathematical model does not conform to the actual situation, the mathematical model must be modified.

Mathematical modeling generally can be divided into six stages: model preparation, model hypothesis, model establishment, model solution, model analysis, model testing.

1) The model preparation stage is mainly to understand the actual background of the problem, to clarify its practical significance, to grasp the various information of the object and to describe the problem model in mathematical language.

2) The hypothesis stage is to simplify the problem according to the characteristics of the actual object and the purpose of the model, and to put forward some appropriate hypotheses in precise language.

3) The most important stage is to establish the model, on the basis of a hypothesis, appropriate mathematical tools are used to depict the mathematical relationship between variables and establish the corresponding data structure.

4) The Model Solution stage is try to use simple mathematical tools to solve the model and use the data obtained to calculate or estimate all the parameters of the model.

5) The model analysis stage is to analyze the results in mathematics.

6) In model checking stage, the results of model analysis are compared with the actual situation to verify the accuracy, rationality and applicability of the model. If the model is in good agreement with the actual situation, the actual meaning of the calculation results should be given and explained; otherwise, the hypothesis should be modified and the process 
of modeling should be repeated again. The process of establishing the mathematical model can be shown in Fig. 1.

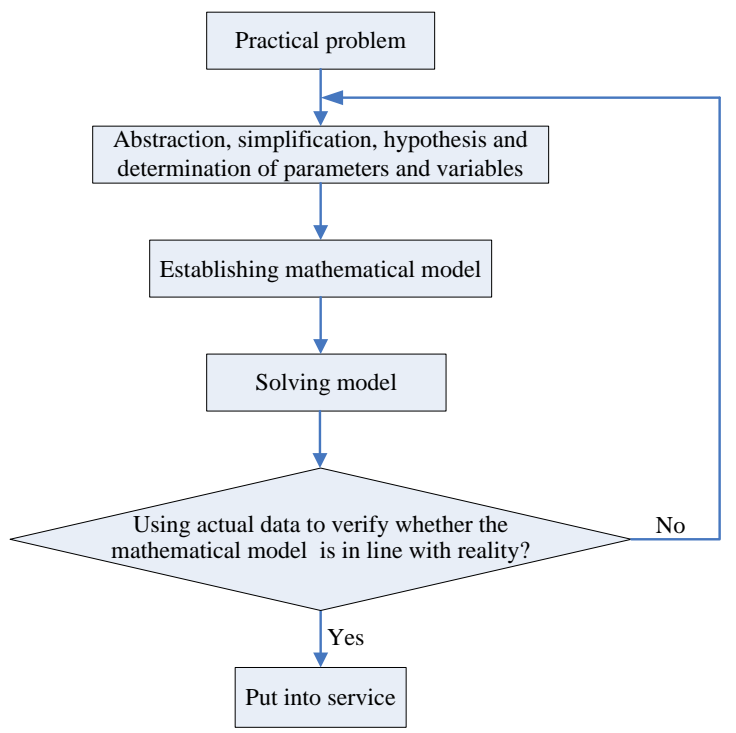

Fig. 1. The process of mathematical modeling

\section{ANALYSIS OF SCIENTIFIC COMPUTING ABILITY IN MATHEMATICAL MODELING PROCESS}

From the previous process of mathematical modeling, we can see that the most important step of mathematical modeling is to establish and solve mathematical models. If the process of establishing mathematical models depends more on the mathematical basis, solving mathematical models depends more on computer knowledge.
In the process of solving mathematical model, we must complete the tasks of determining algorithm, programming, numerical solution and parameters. Among them, the theory and method of optimization have become common methods in various mathematical modeling competitions, such as how to select design parameters in engineering design, so that the design scheme can meet the design requirements and reduce costs; how to allocate limited resources in resource allocation, so that the allocation scheme can meet the basic requirements of all aspects and obtain good economic benefits; and how to find an optimal path from a given starting point to a termination point, and optimize some performance indicators in the running process with the shortest path. In every field of human activity, there are numerous such things.

There are many optimization algorithms for solving this kind of problem, which can be basically divided into two categories: exact algorithm and heuristic algorithm. The exact algorithm can search the solution space thoroughly and get the global optimal solution, such as linear and non-linear programming, dynamic programming, multi-objective programming, integer programming, queuing theory, inventory theory, game theory, decision theory and so on, but the optimization problems applied by such algorithms are limited. Heuristic algorithms are usually used for NP-Hard, NPComplete and other problems, also known as approximation algorithms such as Tabu search, simulated annealing, genetic algorithm, neural network, swarm intelligence and so on ${ }^{[4]}$.

With the advent of the big data era, the research background of practical problems has changed significantly due to the emergence and rapid development of new fields, theories and technologies, as shown in Table ${ }^{[5]}$.

TABLE I. COMPARISON OF TRADITIONAL AND MODERN PROBLEMS

\begin{tabular}{|c|l|l|}
\hline Difference & \multicolumn{1}{|c|}{ Traditional problems } & \multicolumn{1}{|c|}{ Modern problems } \\
\hline $\begin{array}{c}\text { Characteristics of the } \\
\text { problem }\end{array}$ & $\begin{array}{l}\text { It is mainly based on calculus and the scale of the } \\
\text { problem is small. }\end{array}$ & $\begin{array}{l}\text { (1)Discreteness: Based on combinatorial optimization theory. } \\
\text { (2) Uncertainty: stochastic mathematical model. } \\
\text { (3)Semi-structured or unstructured problems: computer simulation and } \\
\text { decision support system. } \\
\text { (4)Large-scale problems: parallel computing, approximation theory. }\end{array}$ \\
\hline Solution method & Traditional optimization methods (exact algorithms) & Modern optimization methods (heuristic algorithms) \\
\hline Pursuing goals & $\begin{array}{l}\text { (1)Pursuing Accuracy: Accurate Solution. } \\
\text { (2) Perfection of Theory: Beautiful Result. }\end{array}$ & $\begin{array}{l}\text { (1)Pursuing Satisfaction: Approximate Solution. } \\
\text { (2)Strong practicability: solving practical problems. }\end{array}$ \\
\hline Evaluation method & $\begin{array}{l}\text { (1) Convergence of the algorithm (From the } \\
\text { perspective of limit) } \\
\text { (2) Convergence rate (linear, superlinear, quadratic } \\
\text { convergence, etc.) }\end{array}$ & Algorithmic complexity \\
\hline
\end{tabular}

Therefore, it is the objective requirement of the times to strengthen the teaching and practice reform of intelligent computing and to study its role in mathematical modeling. It is of great significance to cultivate students' scientific computing ability.

\section{TRAining OF SCIENTIFIC COMPUTING ABILITY IN COMPUTER COURSE TEACHING}

At present, the basic courses of computer culture offered by universities include computer basic knowledge, office software, programming language and computer network technology. Learning and mastering these contents can improve students' ability to use computers to a certain extent, but there is still a big gap with the scientific computing ability that we require students to have.

In order to meet the requirements of scientific development and new-type talents with an innovative spirit and practical ability in the 21st century, it is urgent to construct the teaching plan of intelligent computing in the computer foundation teaching the program in universities. 
For this reason, we take the training of innovative talents as the starting point, and based on the systematic, basic, comprehensive and innovative nature of scientific research teaching and practical teaching, a series of teaching reform methods have been put forward, which have been recognized and praised by domestic colleagues and concerned by teachers and students in colleges and universities.

A. Following up the frontier of disciplines, paying attention to the intersection of multi-disciplines and optimizing teaching contents

The teaching purpose of intelligent computing related courses is to enable students to master the basic knowledge and principles of intelligent computing, master how to deal with massive and complex information, and study new and advanced theories and technologies of intelligent computing. Further, students will understand the application prospects of intelligent computing in the fields of complex system modeling, system analysis, system decision-making, system control, system optimization and system design, and the main application fields of intelligent computing. This will lay a good foundation for further solving practical problems by using intelligent computing methods, and further improve students' scientific computing ability.

Interdisciplinary is the main feature of the development of contemporary science and technology. As far as the intelligent computing related courses are concerned, they are closely related to every branch of modern science, synthesizing knowledge in many fields, from human organisms to genetic changes of natural species, etc. Therefore, in the process of teaching, teachers not only explain the whole and basic knowledge to students, but also pay more attention to introducing the intersection and integration of intelligent computing with other disciplines and their application in the field of production practice, so that students can understand the frontier technology and development trend of this discipline, so as to broaden their horizons.

In the teaching process of intelligent computing related courses, we should cover the following teaching contents from basic principles, design methods to application development, the main contents include: (1) overview of artificial intelligence; (2) search technology; (3) rough set information processing; (4) genetic algorithm; (5) ant colony algorithm; (6) particle swarm optimization; (7) quantum intelligent information processing; (8) cloud computing; (9) Internet of Things technology; (10) Large data analysis technology ${ }^{[6,7]}$.

With the renewal of teaching content, students' knowledge will be further developed, which is conducive to the improvement of students' scientific computing ability.

\section{B. Creating new teaching concepts and establishing new teaching methods and means}

In the process of teaching, traditional teaching methods and means will be gradually changed, mainly in the following aspects $^{[8]}$ :

\section{1) Teaching with the case of smart city construction}

In the teaching reform of intelligent computing-related courses, teaching activities are carried out based on the case of smart city, which is to train students with a large number of actual situations, so that students can analyze the actual problems in the simulated Smart City scenarios.

For example, facing the growing scale of urban traffic network, especially the continuous improvement of rail transit network, a multi-mode intelligent transfer query integration system have been designed and implemented for large-scale urban rail transit network based on Swarm Intelligence Computing.

The main function of the system is to quickly realize the optimization calculation of multi-mode transfer such as distance priority, time priority or transfer priority in rail transit transfer in many large-scale cities, to meet the travel requirements of different residents in different cities, and to promote the equilibrium distribution of dynamic traffic scientifically and effectively.

Let students master and apply what they have learned in the actual scene, so that they can not only cultivate their scientific computing ability, but also develop their ability to solve practical problems.

On this basis, in the teaching process, the analysis of typical cases of the smart city will be improved further, the scene that can stimulate students' creativity will be condensed, and ultimately students' ability of practical management will be cultivated and improved, which can lay a good foundation for future work.

\section{2) Promote initiative in a competitive manner}

As mentioned above, mathematical modeling activities not only require students to have certain mathematical knowledge but also require students to have certain scientific computing ability, so actively organizing students to participate in extracurricular activities such as mathematical modeling competitions, electronic design competitions can lead students to pay more attention to computability, computational complexity, algorithms, data structures, computational strategies, and so on, which is an effective way to improve students' scientific computing ability.

Around the contemporary undergraduate mathematical contest in modeling, students are organized to participate in related competitions such as Shanghai undergraduate computer application competition and National undergraduate computer application ability and information literacy competition.

Through teaching with competitive mode, students' enthusiasm can be mobilized, their sense of teamwork and competition can be cultivated, and their practical operation ability can be exercised. Through the competition, students can deeply grasp the theoretical knowledge of books and the key of modern intelligent information processing technology.

Taking the contemporary undergraduate mathematical contest in Modeling 2017 as an example, some students used the fuzzy C-means clustering algorithm based on hybrid 
genetic simulated annealing, BP neural network and other intelligent computing methods to solve the "Task Pricing of Photo Making Money" and won the first and second prizes in China.

Teaching with competition method meets the needs of the country and society for talents, is an important means to improve students' scientific computing ability, can improve students' comprehensive quality in many aspects, and promote the training process of "Excellent Engineer Program".

\section{CONCLUSION}

Mathematical Contest in Modeling takes solving practical problems as its mainline. These problems involve engineering technology, economic management, social life and other fields. They are very practical and challenging. What we need is not only mathematical knowledge and ability to solve mathematical problems but also comprehensive knowledge and ability in many aspects.

Mathematical modeling can improve students' comprehensive quality from many aspects, which is the consensus of the educational circles. It is in line with the characteristics of the times to strengthen the application of intelligent computing related courses in mathematical modeling. As an important part of teaching quality and teaching reform project in colleges and universities, it is an important means to strengthen quality education, cultivate compound, applied and pioneering talents. It will cultivate more excellent compound intelligent talents to meet the needs of the society, with distinct characteristics and remarkable practical effects.

\section{REFERENCES}

[1] Li Yang, Luo Meilin. New Thoughts on Teaching Mode of Multidisciplinary Interdisciplinary Intelligent Information Processing for Postgraduate[J]. Computer Education, 2016 (10): 113-116. (In Chinese)

[2] Xie Jinxing. Scientifically Organizing Contemporary Undergraduate Mathematical Contest in Modeling to Promote Innovative Talents Training and Mathematical Education Reform [J]. Teaching in Chinese Universities, 2009 (2): 8-11. (In Chinese)

[3] Jiang Qiyuan, Xie Jinxing, Ye Jun. Mathematical Model (4th Edition) [M]. Higher Education Press, 2011. (In Chinese)

[4] Song Wei, Liu Lizhen, Wang Hanshi, et al. New Thoughts on the Teaching Reform of Intelligent Information Acquisition Technology[J]. Computer Education, 2014 (19): 63-65. (In Chinese)

[5] Cai Yanning, Wang Hongqiao, Fan Qinggang, et al. Construction and Practice of Key Graduate Courses in Artificial Intelligence and Application [J].Higher Education Journal, 2016 (17): 185-186. (In Chinese)

[6] Ding Shifei. Artificial Intelligence (2nd Edition) [M]. Beijing: Tsinghua University Press, 2015. (In Chinese)

[7] Shi Zhongzhi. Advanced Artificial Intelligence [M]. 3 Edition. Beijing: Science Press, 2011. (In Chinese)

[8] Tan Yuehui, Wang Hongsheng, Qi Jianfeng, et al. Construction and practice of Artificial Intelligence Principles for Postgraduates [J]. Computer Education, 2012 (18): 35-37. (In Chinese) 